\title{
Estimation of Clear-Air Atmospheric Effective Earth Radius (K-Factor) in Calabar
}

\author{
Isaac A. Ezenugu ${ }^{1}$, Umoren Ifiok Anthony ${ }^{2}$, Okon Abasiama Colman ${ }^{2}$ \\ ${ }^{1}$ Department of Electrical Engineering, Imo State University (IMSU), Owerri, Nigeria \\ ${ }^{2}$ Department of Electrical/Electronic and Computer Engineering, University of Uyo, Akwalbom, Nigeria
}

\section{Email address:}

isaac.ezenugu@yahoo.com (I. A. Ezenugu)

\section{To cite this article:}

Isaac A. Ezenugu, Umoren Ifiok Anthony, Okon Abasiama Colman. Estimation of Clear-Air Atmospheric Effective Earth Radius (K-Factor) in Calabar. American Journal of Software Engineering and Applications. Vol. 2, No. 3, 2017, pp. 35-37.

doi: $10.11648 /$ j.ijics.20170203.12

Received: October 16, 2016; Accepted: January 20, 2017; Published: July 21, 2017

\begin{abstract}
Microwave radio propagation in terrestrial radio links over the years has earned increased application and there has been renewed attention of studies concerning techniques for estimating the probability of multipath fading distributions. Particularly, the secondary radio parameters remain very important in carrying out these estimations especially the concept of effective earth radius. This study was carried out in Calabar, South-south Nigeria with three years atmospheric parameters data obtained from Nigerian Meteorological Agency (NIMET). International Telecommunication recommendation models were used in obtaining point refractivity gradient with which the effective earth radius factor was determined. The result showed a yearly average value of 1.626091667 for the k-factor and yearly average value of -125.50845 for the point refractivity gradient. There are also monthly and seasonal variations in the two parameters. The highest k-factor of 1.8263 occurred in January whereas the least $\mathrm{k}$-factor of 1.3396 occurred in November.
\end{abstract}

Keywords: Radio Propagation, Microwave Radio, Refractivity, Multipath Fading, Effective Earth Radius, K-Factor, Point Refractivity Gradient

\section{Introduction}

Radio wave communication over the years has been in use in greater capacity as compared to other means of communication [1]. This can be seen in both civil and military operations the world over and are applied in transmitting voice, data and video to various location $[2,3$, 4]. In the bid to improve on the coverage, capacity and quality of service for radio wave communication systems, experts have found that the propagation of radio signals through the atmosphere is greatly influenced by the effective earth radius factor $\mathrm{k}[5,6,7,8]$. Particularly, the $\mathrm{k}$-factor is largely dependent on one of the most important parameters of radio wave propagation known as refractivity gradient as considered in the lowest $65 \mathrm{~m}$ from the ground level [9, 10 , 11]. Variations in refractivity may cause radio waves to bend while propagating through dissimilar layers of the atmosphere [12]. Notably, these variations are determined by atmospheric conditions such as pressure, temperature and humidity which tend to vary with respect to geographical location as well as time of the year. For microwave system design, some parameters such as effective earth radio factor, $\mathrm{k}$ and the point refractivity gradient, $\mathrm{dN} 1$ must be set carefully to optimize the system performance. Also, for such locations where atmospheric data were not available, $\mathrm{k}$-factor value of $4 / 3$ is taken as a standard value and estimated values of dN1 are also provided by ITU tables for point refractivity for such conditions [13]. Consequently, in this paper, three years atmospheric parameters data for Calabar, in the South-south Nigeria is used to determine the point refractivity gradient and then the effective earth radius factor, also called k-factor. The main focus is to identify the temporal distribution of the $\mathrm{k}$-factor in Calabar.

\section{Effective Earth Radius}

According to ITU [14] effective earth radius is the radius of a theoretical spherical earth, that has no atmosphere, for this 
reason propagation paths or radio waves follow straight lines; at the same time heights and distances measured on ground are the same with the situation where it is the actual earth with atmosphere that has a constant vertical refractivity gradient [15]. The concept of effective earth as considered in radio and radar communication is seen to be a theoretical value used for the earth radius instead of the actual earth radius; the effective earth radius is used to correct for refraction that is caused by the atmosphere. The effective earth radius factor $(\mathrm{k})$ can be calculated $[12,14,16,17]$;

$$
\mathrm{K}=\left[1+\frac{\left(\frac{d N}{d h}\right)}{157}\right]^{-1}
$$

Variations in atmospheric refractive conditions cause changes in effective earth radius as well as changes in $\mathrm{k}-$ factor from its median value which is about $4 / 3$ for standard atmosphere

[18]. When the atmosphere is adequately sub-refractive (that means the refractive index gradient has large positive values, the $\mathrm{k}$ - factor values are low) the ray paths will be bent in such a way that the earth will appear as if it will obstruct the direct transmission path between receiver and transmitter, and this gives rise to diffraction fading [19]. Kfactor statistics for a single point can be determined from measurement or predictions of the refractive index gradient of the atmosphere.

\section{Determination of $\mathbf{K}$ - Factor}

The determination of $\mathrm{K}$ - factor in greater extent depend on point refractivity gradient which the later as to be consider for proper estimation of the $\mathrm{k}$ - factor. The refractivity, $\mathrm{N}$ is related to the refractive index, $\mathrm{n}$ of air as $[20,8,21,22]$;

$$
\mathrm{N}=(n-1) 10^{6}=77.6\left(\frac{P}{T}\right)+3.732\left(10^{5}\right)\left(\frac{e}{T^{2}}\right)
$$

Where $\mathrm{T}$ is the absolute temperature $(\mathrm{K})$

$\mathrm{P}$ is the atmospheric pressure (hpa)

e. is the atmospheric water vapour pressure (hpa). The water vapour pressure is calculated from the relative humidity and saturated water vapour using the expression $[8,20,21,22$, 23];

$$
e=H\left(\frac{6.1121 \exp \left(\frac{17.502 t}{t+240.97}\right)}{100}\right)
$$

To obtain the point refractivity gradient $\mathrm{dN} / \mathrm{dh}$, the following estimation is used [20, 8, 21, 22];

$$
\mathrm{G}=\frac{d N}{d h}=\frac{N 2-N 1}{h 2-h 1}
$$

Where $\mathrm{N}_{2}$ is the refractivity at the lowest $65 \mathrm{~m}$ from ground level, $N_{1}$ is the refractivity at the ground level and $h_{1}$ is the ground level. Hence, the $\mathrm{k}$ - factor is now obtained using equation 1 .

\section{Results and Discussion}

Table 1. Refractivity gradient and effective earth radius for various months.

\begin{tabular}{lll}
\hline Month & K-Factor for Calabar & DN \\
\hline January & 1.8263 & -33.0018 \\
February & 1.7748 & -74.3628 \\
March & 1.3796 & -256.565 \\
April & 1.5851 & -111.329 \\
May & 1.8604 & -25.4683 \\
June & 1.7793 & -75.5295 \\
July & 1.8025 & -38.6429 \\
August & 1.675 & -75.6012 \\
September & 1.6292 & -92.5154 \\
October & 1.4566 & -186.856 \\
November & 1.3396 & -305.269 \\
December & 1.4047 & -230.961 \\
Yearly Average & 1.626092 & -125.508 \\
\hline
\end{tabular}

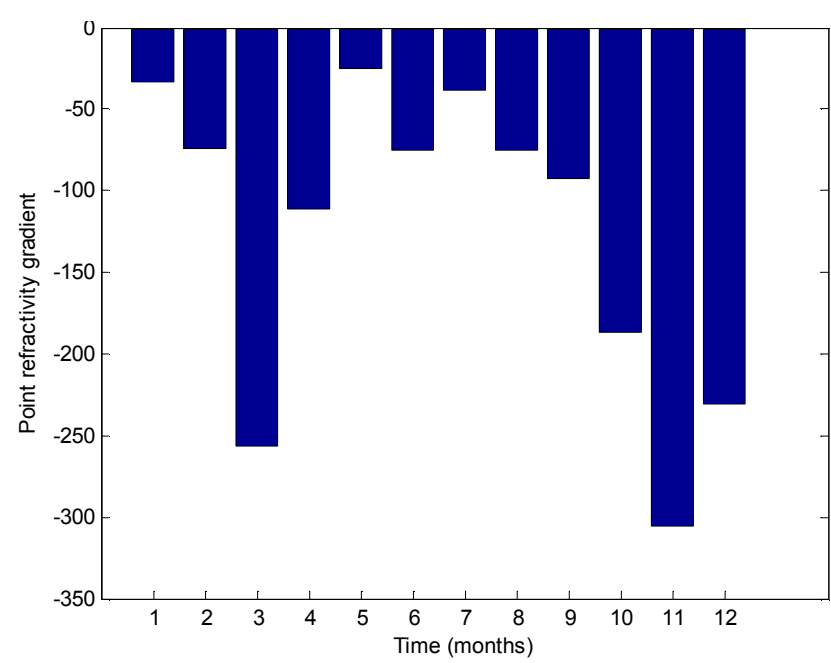

Figure 1. Point refractivity gradient for various months in Calabar.

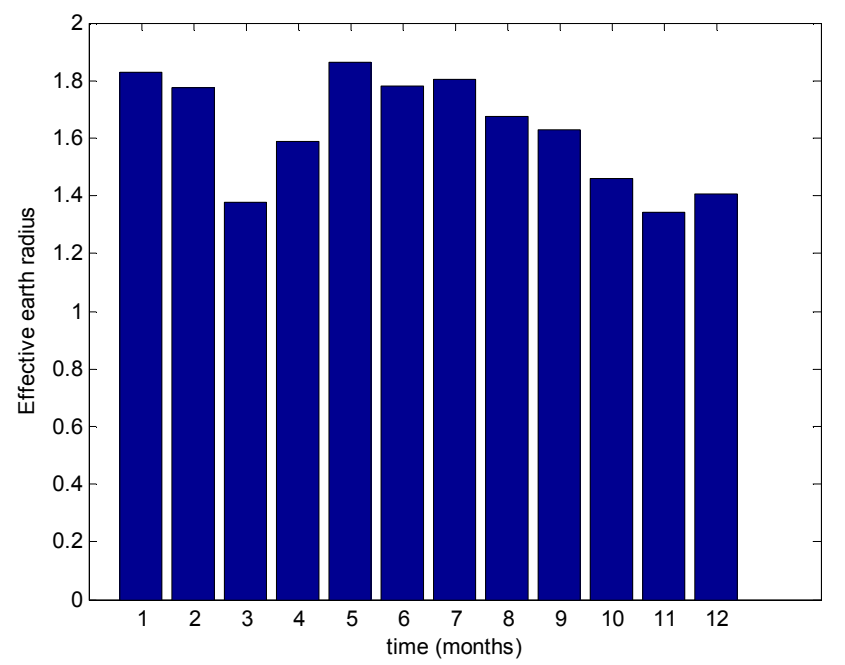

Figure 2. Shows effective earth radius for different months in Calabar.

From the result distribution, it shows monthly variation between 1.34 and 1.82 of effective earth radius with peak value occuring in January and least value in November. The result also show that the point refractivity gradient has periodic monthly variation. 


\section{Conclusion}

Point refractive gradient and effective earth radius has been calculate for Calabar using local NIMET radiosonde data for the time span between 2012 and 2014. The calculated values of effective earth radius shows a variation between 1.3 and 1.8 while the point refractivity gradient varies between -305 and -33. From the result distribution, it shows that the point refractivity gradient is relatively high in the rainy period between April and October as compared to the remaining months of dry season; this is as a result of high moisture content in the atmosphere. However, the monthly or seasonal mean effective earth radius factor and point refractivity gradient can be used for planning wireless links.

\section{Acknowledgement}

The authors would like to express their heartfelt gratitude to Nigerian Meteorological Agency for providing meteorological data used for this work.

\section{References}

[1] Mitra, A. (2009). Lecture notes on mobile communication. A Curriculum Development Cell project Under QIP, IIT Guwahati.

[2] Ogunjemilua, K., Davies, J. N., Picking, R., \& Grout, V. (2009). An Investigation into Signal Strength of 802. $11 \mathrm{n}$ WLAN.

[3] Lanbo, L., Shengli, Z., \& Jun - Hong, C. (2008). Prospects and problems of wireless communication for underwater sensor networks. Wireless Communications and Mobile Computing, 8 (8), 977-994.

[4] Cawte, M. (1996). Making radio into a tool for war. Unpublished paper, University of Leeds, UK. Retrieved from https://docs.google.com/viewer.

[5] Falodun, S. E., \& Okeke, P. N. (2013). Radiowave propagation measurements in Nigeria (preliminary reports). Theoretical and Applied Climatology, 113 (1-2), 127-135.

[6] Ekpe, O. E., Agbo, G. A., Ayantunji, B. G., Yusuf, N., \& Onugwu, A. C. (2010). Variation of Tropospheric Surface Refractivity at Nsukka in South Eastern Nigeria. Nigerian Journal of Space Research, 7, 42-48.

[7] Onuu, M. U., \& Adeosin, A. (2008). Investigation of propagation characteristics of UHF waves in Akwa Ibom State, Nigeria. Indian Journal of Radio \& Space Physics, 37, 197-203.

[8] Adeyemi, B., \& Emmanuel, I. (2011). Monitoring tropospheric radio refractivity over Nigeria Using CM-SAF data derived from NOAA-15, 16 and 18 Satellites. Indian Journal of Radio \& Space Physics, 40 (6), 301-310.

[9] Falade, J. A., Adesanya, S. O., \& Akinyemi, G. A. (2014). Variability of meteorological factors on surface refractive index over Mowe, a coastal area in Nigeria. Indian Journal of Radio \& Space Physics, 43, 355-361.

[10] Nyete, A. M., \& Afullo, T. J. O. (2013). Seasonal distribution modeling and mapping of the effective earth radius factor for microwave link design in south africa. Progress In Electromagnetics Research B, 51, 1-32.

[11] Grabner, M., \& Kvicera, V. (2011). Atmospheric refraction and propagation in lower troposphere. INTECH Open Access Publisher.

[12] Abu-Almal, A., \& Al-Ansari, K. (2010). Calculation of effective earth radius and point refractivity gradient in UAE. International Journal of Antennas and Propagation, 2010.

[13] AbouAlmal, A., Abd-Alhameed, R. A., Jones, S. M., \& Al-Ahmad, H. (2015). New Methodology for Predicting Vertical Atmospheric Profile and Propagation Parameters in Subtropical Arabian Gulf Region. Antennas and Propagation, IEEE Transactions on, 63 (9), 4057-4068.

[14] ITU (1994) International Telecommunications Union (ITU-R, 1994). Definition of terms relating to propagation in ionized media. International Telecommunications Union, Geneva, Recommendation of ITU-R PN. 310-9.

[15] Skolnik M. (2001). Introduction to radar systems. $3^{\text {rd }}$ edition, Mcgraw-Hill, New York.

[16] Odedina, P. K., \& Afullo, T. J. (2006). On the k-factor distribution and diffraction fading for Southern Africa. SAIEE Africa Research Journal, 97 (2).

[17] Okoro, O. N., \& Agbo, G. A. (2016). The effect of variation of meteorological parameters on the tropospheric radio refractivity for minna. Global Journal of Science Frontier Research, 12 (2-A).

[18] ITU (1997) International Telecommunications Union: ITU-R Recommendation P. 530-7, Propagation data and prediction methods required for the design of terrestrial line-of-sight systems, Geneva, 1997.

[19] ITU (1999) ITU-R Recommendation P. 530-8. Propagation data and prediction methods required for the design of terrestrial line-of-sight systems. -ITU, Geneva, 1999. -34 p.

[20] Bean B. R and Dutton E. J. (1966). Radio meteorology. US department of commerce, National Bereau of standard monograph. Dover publication Co. New York pg 92-100.

[21] Gao, J., Brewster, K., \& Xue, M. (2008). Variation of radio refractivity with respect to moisture and temperature and influence on radar ray path. Advances in Atmospheric Sciences, 25 (6), 1098-1106.

[22] Seybold J. S. (2007). Introduction to RF propagation. WileyInterscience. John Willey and Sons, Inc.: pp. 116-118.

[23] Adediji A. T. and Ajewole M. O. (2011). Vertical profileof radio refractivity gradient in Akure, South west Nigeria. Progress in electromagnetic research C, Vol. 4, pg 157-168. 